\title{
Robot Path Planning using Swarm Intelligence: A Survey
}

\author{
Narendra Singh Pal \\ School of Information Technology, \\ RGPV, Bhopal, India
}

\author{
Sanjeev Sharma \\ School of Information Technology, \\ RGPV, Bhopal, India
}

\begin{abstract}
The concept of swarm intelligence is based on the collective social behaviour of decentralized body, either natural or artificial like ant, fish, bird, bee etc. Swarm intelligence has gained very high priority among the researchers from different field like commerce, science and engineering. Multiple editions of swarm intelligence's techniques made it suitable for optimization problems. In this paper, we have present a review of 4 different algorithms based on swarm intelligence for finding the path by mobile robot. Path planning is an interesting problem in mobile robotics. It is about finding the shortest, collision free and smooth path by the robot form predefined starting position to fixed goal position in an environment with obstacles either moving or stationary. This problem is difficult to solve particularly in the case of dynamic environment where the optimal path needs to be rerouted in real time when a new obstacle come out.
\end{abstract}

\section{KEYWORDS}

Robot Path Planning, Swarm Intelligence, Moving Obstacles, Dynamic Environment, Collision avoidance, Convergence, Optimization.

\section{INTRODUCTION}

Swarm Intelligence (SI) is the property of a system whereby the collective behaviours of unsophisticated agents interacting locally with their environment cause coherent functional global patterns to emerge. SI provides a basis with which it is possible to explore collective (or distributed) problem solving without centralized control or the provision of a global model. In particular, the discipline focuses on the collective behaviours that result from the local interactions of the individuals with each other and with their environment.

Swarm intelligence, is composed by three main principles: evaluation, comparing and imitation. Evaluation is able to identify what is positive or negative in nature. Learning won't happen unless beings are capable of evaluate the attractive and repulsive characteristics of the environment. In comparison, living beings compare themselves with other beings as results of these comparisons may become a motivation to learning and/or modification. Imitation is an effective form of learning. However, very few animals, in nature, are capable of imitating, in fact, only human beings and some species of birds are capable of such action [1].

The typical swarm intelligence system has the following properties:

- Swarm is composed of many individuals;

- Generally the individuals are homogeneous (either all identical or they belong to a few typologies);

- The interactions among the individuals are on local information that the individuals exchange directly or via the environment, by simple behavioural rule.

- The overall behaviour of the system results from the interactions of individuals with each other and with their environment, i.e, the group behavior selforganizes.

Swarm Intelligence can be described by considering five fundamental principles [2].

- Proximity Principle: the individual should be able to carry out simple space and time computations.

- Quality Principle: the individual should be able to respond to quality factors in the environment.

- Diverse Response Principle: the individual should not commit its activity along excessively narrow channels.

- Stability Principle: the individual never change its mode of behavior when the environment changes.

- Adaptability Principle: the individual should be able to change its behavior mode when the computational price is worth.

Swarm intelligence system can act in a coordinated way without the presence of an external coordinator. Swarm intelligence added a new property in artificial intelligence to study the collective behaviour and emergent properties of complex systems with in predefined environment[3]. In recent years a number of swarm based optimization techniques have been proposed among which we have discuss about the Particle swarm optimization(PSO), Ant colony optimization(ACO), Artificial bee colony optimization(ABC) and Firefly Algorithm(FA) in terms of robot path planning.

Robot path planning is an important problem in navigation of mobile robots. The aim is to find an optimal and collision-free path from a predefined start position to a target point in a given environment. Generally, there are many paths for robot to reach the target, but in fact the best path is selected according to some guide line. These guide lines are: shortest path, least energy consuming or shortest time. The field robot path planning was launched at the middle of the 1960's [4][5].

The problem of path planning is very active area of research. This problem is solved by many conventional methods such as Artificial Potential Field [6], Neural Network [7], Distance Wave Transform [8], A* algorithm [9], D* algorithm [10] and etc, proposed by previous researchers have changed and evolved to other variation of path planning approaches that is based on approaches categorized as artificial intelligence [11].

In computational complexity theory, path planning is classified as an NP complete problem [12]. That is, the computational time that is required to solve such problem increases dramatically (usually in an exponential rate) when the size (or dimension) of the problem increases.

The rest of this paper is organized as follows: Section 2 describes the review of Particle Swarm Optimization, Ant Colony Optimization, Artificial Bee Colony Optimization and Firefly Algorithm. Section 3 describes the comparison of all 4 algorithms. Section 4 presents an Advantages and Disadvantages of ACO, PSO and ABC. Section 5 concludes the paper and Future Work. 


\section{METHODS OF PATH PLANNING}

\subsection{Particle Swarm Optimization (PSO)}

Particle Swarm Optimization is a population based optimization technique proposed by Dr. Kennedy and Dr. Earhart in 1995. It is inspired by the social behaviour of bird flocking and schooling of fishes [13]. In PSO, each 'bird' or 'fish' act as a particle and the 'flock' or 'school' is names as swarm. In PSO each particle communicates with other particle while learning their own experience and it randomly searches the path in the given environment by updating itself with its own memory. The implementation of PSO is simple and if any path is exists in the environment it will found definitely by the PSO.

PSO is generally applied to many optimization areas due to its unique searching mechanism, simple concept, computational efficiency, and easy implementation. Each particle in the swarm represents a solution in a high-dimensional space with four vectors, its current position, best position found so far, the best position found by its neighbourhood so far and its velocity [2].

Suppose D is the dimension of the searching space and $\mathrm{N}$ is the number of particle. PSO is initialized with a population of random particles which distribute uniformly around search space at first. Assuming that the position and velocity of the $\boldsymbol{i}^{\boldsymbol{t h}}$ particle is represented as $\boldsymbol{X}_{\boldsymbol{i}}=\left(\boldsymbol{x}_{\boldsymbol{i 1}}, \boldsymbol{x}_{\boldsymbol{i} \mathbf{2}} \ldots \ldots \boldsymbol{x}_{\boldsymbol{i D}}\right)$ and $\boldsymbol{V}_{\boldsymbol{i}}$ $=\left(v_{i 1}, v_{i 2} \ldots \ldots v_{i D}\right)$ respectively, each particle is maintains a memory of its previous best position denoted by $\boldsymbol{P}_{\boldsymbol{i b e s t}}=\left(\boldsymbol{p}_{\boldsymbol{i} 1}, \boldsymbol{p}_{\boldsymbol{i} 2} \ldots \ldots \boldsymbol{p}_{\boldsymbol{i D}}\right)$ and the best position of the population denoted as $\boldsymbol{P}_{\boldsymbol{g} b e s t}$ $=\left(\boldsymbol{p}_{g 1}, \boldsymbol{p}_{g 2} \ldots \ldots \boldsymbol{p}_{g D}\right)$.

Each particle updates its position and velocity according to the following equations:

$V_{i}^{K+1}=\mathrm{w}_{i}^{K}+c_{1} r_{1}\left(P_{\text {ibest }}-X_{i}^{K}\right)+c_{2} r_{2}\left(P_{\text {gbest }}-X_{i}^{K}\right)$

$X_{i}^{K+1}=X_{i}^{K}+V_{i}^{K+1}$

where $\mathrm{k}=1,2, \ldots \mathrm{K}$ and $\mathrm{K}$ is the maximum number of iterations; $\mathrm{i}=1,2, \ldots \mathrm{N}$ and $\mathrm{N}$ is the number of particles; $\mathrm{w}$ is the inertia weight, it is responsible for dynamically adjust the speed of the particles; $\boldsymbol{c}_{\mathbf{1}}$ and $\boldsymbol{c}_{\mathbf{2}}$ are two positive constants, generally we choose $\boldsymbol{c}_{\mathbf{1}}=\boldsymbol{c}_{\mathbf{2}}=2 ; \boldsymbol{r}_{\mathbf{1}}$ and $\boldsymbol{r}_{\mathbf{2}}$ are two random functions in the range from 0 to 1 [14][15].

The basic PSO algorithm is summarized in the following steps, which is also shown in fig 1 .

Step 1- Each particle of the swarm is initialized in the search environment containing a target and an obstacle, with random values for position and velocity.

Step 2 - Evaluate the fitness value for each particle.

$$
\text { Fitness }=\text { Euclidean }(\mathrm{x}, \mathrm{y})+\text { Euclidean }(\mathrm{y}, \mathrm{z})
$$

where $\mathrm{x}$ is the current coordinates of the individual particle, $\mathrm{z}$ is the target coordinates and $\mathrm{y}$ is the intermediate position to go from $\mathrm{x}$ to $\mathrm{z}$.

Step 3 - Compare the value obtained from the fitness function with its previous best fitness $\boldsymbol{p}_{\boldsymbol{i}}$ to find out next possible coordinate position. If the value of fitness function is better than $\boldsymbol{p}_{\boldsymbol{i}}$ then this new value take the place of $\boldsymbol{p}_{\boldsymbol{i}}$

Step 4 - If the value of $\boldsymbol{p}_{\boldsymbol{i}}$ is better than $\boldsymbol{p}_{\boldsymbol{g}}$ then $\boldsymbol{p}_{\boldsymbol{g}}=\boldsymbol{p}_{\boldsymbol{i}}$.

Step 5 - Update the position and velocity of the particle by equations (1) and (2) respectively.
Step 6 - Until the convergence is reached, repeat step 2 to 5 .

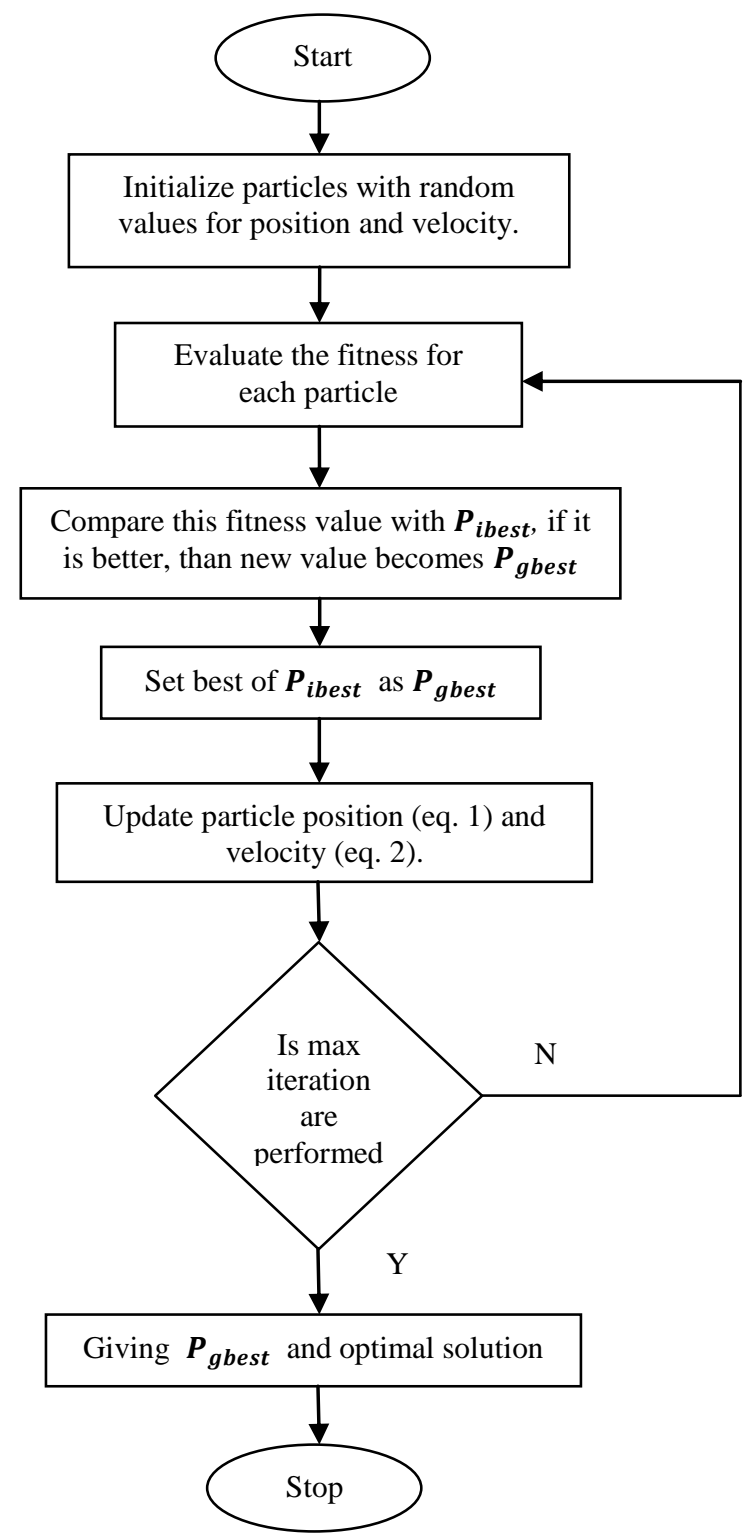

Fig 1: Flow chart of basic PSO algorithm

\subsection{Ant Colony Optimization (ACO)}

Ant Colony Optimization (ACO) algorithms have been proposed by M. Dorigo in 1992 in his Ph. D. Dissertation. It is developed to show the behaviour of real ants to provide heuristic solutions for optimization problem. It solves the problem of path planning in mobile robot by using the ability of optimization in the process of ant searching food

ACO simulates the behavior of ant colonies when they are searching for food in the environment and finding the most efficient routes from their nests to food sources. During motion, ants leave some chemical substance, which we call "pheromone", on the route that they have passed. A pheromone is a type of chemical that stimulates a natural behavioral response to the other ant group. The subsequent ants would choose a path based on the amount of pheromones present on all possible motion paths from the start position (nest) moving to the target position (food) [16] 
Ants can also perceive the pheromone when they pass the route, and their actions could be influenced by the concentration of pheromone. In this way, the shorter of the path, the more frequent visited by ants, the more pheromone accumulated on the path [17]. This process will be lasted until all the ants select the shortest path.

Furthermore, the ant colony possesses better ability to adapt them to the environment around them. Fig. 1 shows that the ants can find the optimum route again quickly when a barrier suddenly appears in the path they pass [18].

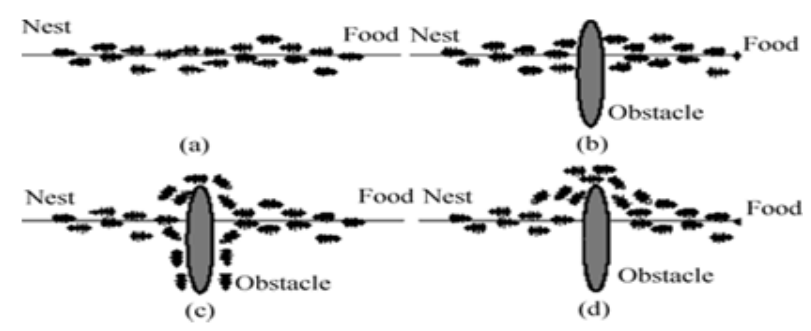

Fig 2: Self-adaptive behavior of ant colony

(a) Real ants follow a path between nest and food source;

(b) An obstacle appears on the path: ants choose whether to turn left or right with equal probability;

(c) Pheromone is deposited more quickly on shorter path;

(d) All ants have chosen shorter path.

In general, the $\boldsymbol{k}^{\text {th }}$ ant moves from state $x$ to state $y$ with probability

$p_{x y}^{k}=\frac{\left(T_{x y}^{a}\right)\left(n_{x y}^{b}\right)}{\sum\left(T_{x y}^{a}\right)\left(n_{x y}^{b}\right)}$

Where,

$\boldsymbol{T}_{x y}$ is the amount of pheromone deposited for transition from state $x$ to $y, 0 \leq \alpha$ is a parameter to control the influence of $\boldsymbol{T}_{x \boldsymbol{y}}, \boldsymbol{n}_{\boldsymbol{x} \boldsymbol{y}}$ is the desirability of state transition $x y$ (a priori knowledge, typically $1 / \boldsymbol{d}_{\boldsymbol{x} y}$, where $d$ is the distance) and $\mathrm{b} \leq$ 1 is a parameter to control the influence of $\boldsymbol{n}_{\boldsymbol{x} y}$.

When all the ants have completed a solution, the trails are updated by

$T_{x y}^{k}=(1-p) T_{x y}^{k}+\Delta T_{x y}^{k}$

where

$\boldsymbol{T}_{\boldsymbol{x} \boldsymbol{y}}^{\boldsymbol{k}}$ is the amount of pheromone deposited for a state transition xy, $\boldsymbol{p}$ is the pheromone evaporation coefficient and $\Delta \boldsymbol{T}_{x y}^{\boldsymbol{k}}$ is the amount of pheromone deposited,

The basic ACO algorithm is summarized in the following steps, which is also shown in fig 3 .

Step 1 - Set up the free space model of working environment and mention the start and end point.

Step 2 - Find the best point for the next move of ants based on eq .(4).

Step 3 - According to the transition probability of each unit, generate several paths from starting point to the destination, each represents a tour of an ant.

Step 4 - Measure the length of each path and update pheromone concentration of all units by eq. (5).
Step 5 - Modify each possible path by align trails of all ants having travelled and calculate the length of the modified path. If the length of the modified path is shorter than the length of current shortest path, then replace it.

Step 6 - Iterate the above process until all ants' trails focus into the globally optimal path.

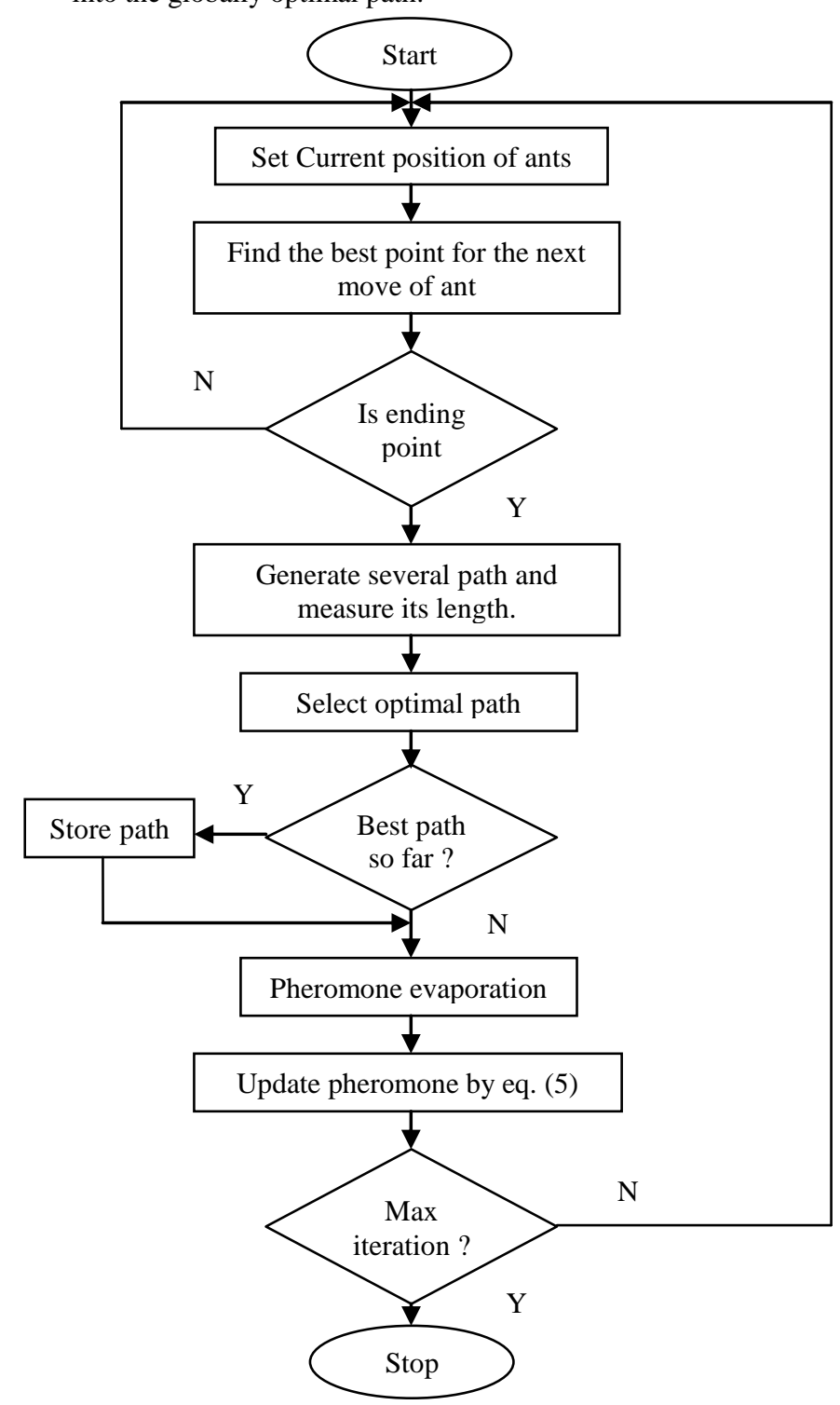

Fig 3: Flow chart of basic ACO algorithm

\subsection{Artificial Bee Colony (ABC)}

The artificial bee colony (ABC) is a population based heuristic algorithm introduced by Dervis Karaboga in 2005 for solving constrained optimization problem [19]. It is inspired by collective behaviour of honeybees to find food sources around the hive. The colony of artificial bees consist of three groups of bees: employed bees, onlooker bees and scouts bees [20].

- Employed bees: At the starting, the colony sends employed bees to promising flower patches. These bees get flower nectar and carry them to the hive. Then they deposit their nectar and go to one spot inside the hive called 'dance floor' for communicating the information with other bees.

The dance which is performed by honey bees is of two types: 
a) Round dance: This dance is performed, when the region visited by a employed bees is near to the hive. It contains information about the nectar quality of visited flower patch so the other bees can find its location by their smelling sense and they get out of the hive.

b) Waggle dance: This dance is performed, when the region visited by the employed bees if not near to the hive. It contains three pieces of information about the flower patch: the direction in which it can be found, its distance from the hive, and its quality.

- Onlooker bees: These bees watch the dances in the hive and choose the best flower patches to go for. The flower patches, which have higher quality, attract more bees than lower quality flower patches.

- $\quad$ Scout bees: This bees carrying out random search of a food search around the hive spontaneously due to some internal motivation.

The number of employed bees is equal to the number of food sources. If food source is exhausted by the employed bees, then onlooker bees become a scout. In artificial bee colony algorithm, the position of a food source represent a possible solution to the optimization problem and the nectar amount of a food source corresponds to the quality (fitness) of the associated solution. The number of the employed bees or the onlooker bees is equal to the number of solutions in the problem [21].

As the nectar amount of a food source increases, the probability of that food source is chosen by an onlooker increases, too. Hence, the dance of employed bees carrying higher nectar recruits the onlookers for the food source areas with higher nectar amount. After arriving at the selected area, they choose a new food source in the neighbourhood of the one in the memory depending on visual information. This information is based on the comparison of food source positions [22]. If the new food has an equal or better nectar than the old source, it is replaces the old one in the memory. Otherwise, the old one is retained in the memory [2].

The first step in using bee colony algorithm is to make an initial path. To create an initial path we assume that the robot moves in a direct line from the starting point to the target. Initial path has some breakpoints, depends on number of obstacles and their shape. Breakpoints are a point that two successive straight lines of the path meet each other. Each breakpoint of the path is a candidate as a food sources. These bees are put randomly in the neighboured of the breakpoints and the point where bees are placed is called 'new point'.

There are two types of methods to create a new path using a new point. First method is to consider this point as a new breakpoint and change the previous breakpoint of the path with this point. Second method is to create a path from starting point to this new point and another path from the new point to the target. These two methods should be performed and the shorter path of two created paths be selected as the new path.

The basic $\mathrm{ABC}$ algorithm is summarized in the following steps, which is also shown in fig 3 .

Step 1 - Create an initial path. This path goes directly from starting point to the target and turns obstacles if encounter them.

Step 2 - Calculate the length of initial path.
Step 3 - Send employed bees to neighbourhood of breakpoints and calculating fitness of new paths.

Step 4 - Send onlooker bees to neighbourhood of selected breakpoints for exploitation and calculating fitness of new paths.

Step 5 - Send scout bees to neighbourhood of breakpoints randomly for exploration and finding new paths.

Step 6 - Till the optimal path is not found, repeat step 3 to 5 .

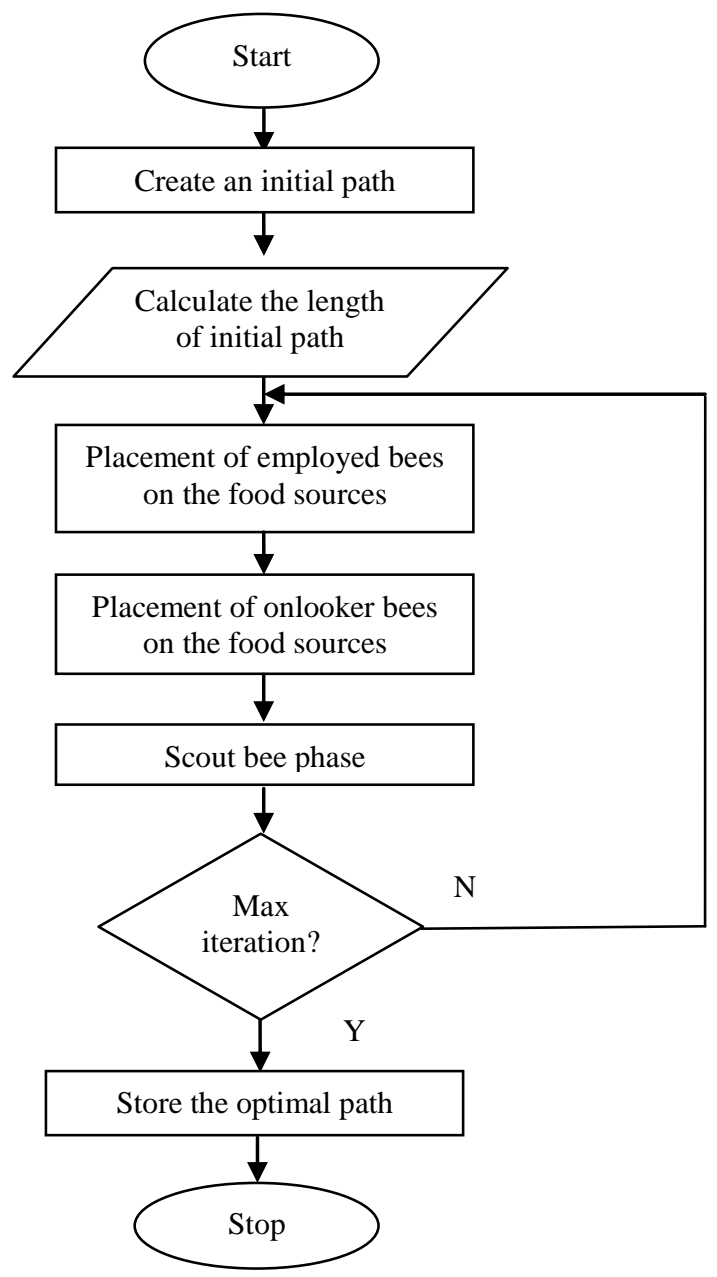

Fig 4: Flow chart of basic ABC algorithm

\subsection{Firefly Algorithm (FA)}

The firefly algorithm (FA) is a metaheuristic algorithm developed by the author Xin-She Yang in 2008. It is inspired by the flashing behaviour of fireflies. The Firefly Algorithm (FA) is a population-based technique to find the global optimal solution based on swarm intelligence, investigating the foraging behaviour of fireflies. The primary purpose for a firefly's flash is to act as a signal system to attract other fireflies.

Similar to other metaheuristics optimization methods, firefly algorithm generates random initial population of feasible candidate solutions. All fireflies of the population are handled in the solution search space with the aim that knowledge is collectively shared among fireflies to guide the search to the best location in the search space. Each particle in the population is a firefly, which moves in the multi-dimensional search space with an attractiveness that is dynamically 
updated based on the knowledge of the firefly and its neighbours [23].

For simplicity, we can summarize these flashing characteristics $[24,25,26,27,28,29]$ as the following three rules:

- All fireflies are unisex, so that one firefly is attracted to other fireflies regardless of their sex.

- Attractiveness is proportional to their brightness, thus for any two flashing fireflies, the less bright one will move towards the brighter one. The attractiveness is proportional to the brightness and they both decrease as their distance increases. If no one is brighter than a particular firefly, it moves randomly.

- The brightness of a firefly is affected or determined by the landscape of the objective function to be optimised.

Initial population of fireflies in the conventional firefly algorithm is generated from an objective function.

$$
P(f)=\left(f_{1}, f_{2}, \ldots \ldots f_{n}\right)
$$

Accordingly, the intensity of their flashing light is determined from the function. This can be calculated as:

$$
L_{i}=L_{o} e^{(-u d)^{2}}
$$

where,

$$
\begin{aligned}
& \boldsymbol{L}_{\boldsymbol{i}}=\text { Light intensity at ith iteration } \\
& \boldsymbol{L}_{\boldsymbol{o}}=\text { Initial light intensity, } \\
& \boldsymbol{u}=\text { Light absorption coefficient, } \\
& \boldsymbol{d}=\text { distance between two firefly. }
\end{aligned}
$$

The distance between two fireflies $\boldsymbol{f}_{\boldsymbol{i}}$ and $\boldsymbol{f}_{\boldsymbol{j}}$ is calculated as:

$$
d_{i j}=\left\|f_{i}-f_{j}\right\|
$$

The initial value of the flashing light absorption parameter is assigned a fixed value, and during the optimization process this parameter is modified according to the performance of optimization. Modification of the flashing light absorption parameter is the key factor to converge the algorithm, and in most of the cases it is considered as a fixed value. Now the algorithm starts its optimization process till the end of generation. First any one of the generated population is considered as a brightest firefly, and the rest of the fireflies are then moved towards the brightest firefly. During the process the distance and attractiveness of each firefly from brighter one is calculated, and it affects the process of movement for each firefly differently. On successful completion of this moving procedure the fireflies are ranked according to their performance [24].

The basic Fireflies algorithm is summarized in the following steps, which are also shown in fig 4.
Step 1 - Each individual generate its strength, state of motion and visual range randomly. The state of motion of the particle includes the location in space velocity and speed limit.

Step 2 - Searching neighbours to calculate attractiveness.

Step 3 - To determine the state of motion. Comparing the one with the best attractiveness with itself.

Step 4 - If attractiveness is better than itself then change the state of motion by one.

Step 5 - Else, maintaining its state of motion, random motion.

Step 6 - Till the termination is condition is not satisfied, repeat step 2 to 5 .

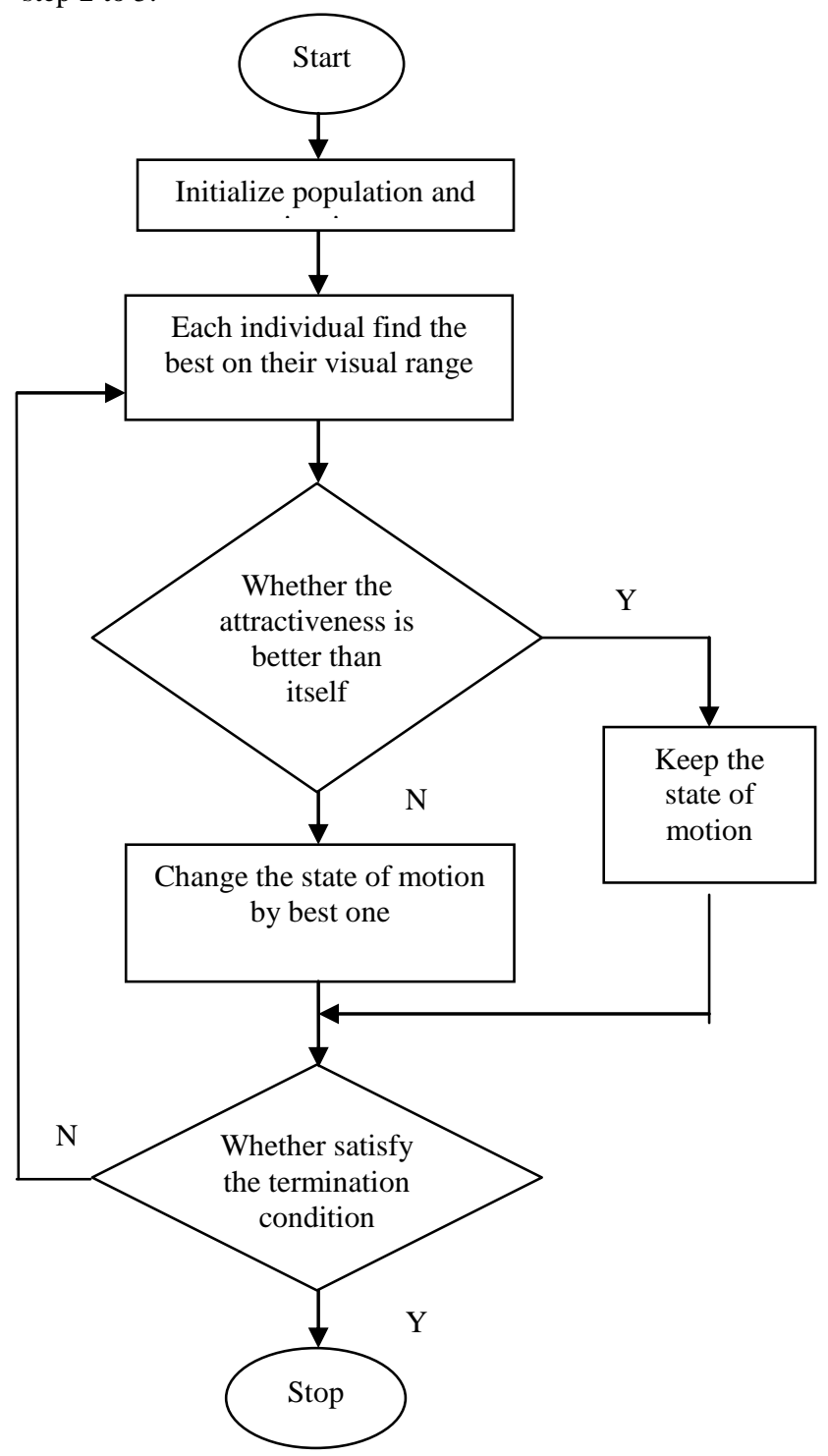

Fig 5: Flow chart of basic FA algorithm 


\section{COMPARISON OF PSO, ACO, ABC \& FA}

\begin{tabular}{|c|c|c|c|c|}
\hline Parameter & PSO & $\mathrm{ACO}$ & $\mathrm{ABC}$ & FA \\
\hline Proposed by & $\begin{array}{l}\text { Dr. Kennedy and Dr. } \\
\text { Earhart in } 1995\end{array}$ & M. Dorigo in 1992 & Dervis Karaboga in 2005 & X. S. Yang in 2008 \\
\hline Inspired by & $\begin{array}{l}\text { Bird flocking or Fish } \\
\text { schooling }\end{array}$ & $\begin{array}{l}\text { Behavior of Ant } \\
\text { colonies }\end{array}$ & $\begin{array}{l}\text { Collective behaviour of } \\
\text { Honeybees }\end{array}$ & $\begin{array}{l}\text { Behavior and } \\
\text { motion of fireflies }\end{array}$ \\
\hline Based on & $\begin{array}{l}\text { Communication between } \\
\text { particle }\end{array}$ & Pheromone trails & $\begin{array}{l}\text { Mysterious dance inside } \\
\text { the hive }\end{array}$ & $\begin{array}{l}\text { Flashing light of } \\
\text { fireflies }\end{array}$ \\
\hline Applied to & $\begin{array}{l}\text { Continuous optimization as } \\
\text { well as discrete problems }\end{array}$ & $\begin{array}{l}\text { Discrete combinatorial } \\
\text { optimization problems }\end{array}$ & $\begin{array}{l}\text { Constraint and } \\
\text { unconstraint optimization } \\
\text { problems }\end{array}$ & $\begin{array}{l}\text { Multimodal } \\
\text { optimization } \\
\text { applications }\end{array}$ \\
\hline $\begin{array}{l}\text { Solutions } \\
\text { represented by }\end{array}$ & $\begin{array}{l}\text { The positions of the } \\
\text { particles }\end{array}$ & $\begin{array}{l}\text { The path constructed } \\
\text { by the ants }\end{array}$ & $\begin{array}{l}\text { The position of bee's in } \\
\text { the neighbourhood of } \\
\text { breakpoint. }\end{array}$ & $\begin{array}{l}\text { Agent movements } \\
\text { along line-of-sight } \\
\text { with a neighbor }\end{array}$ \\
\hline $\begin{array}{l}\text { Knowledge } \\
\text { stored in }\end{array}$ & $\begin{array}{l}\text { The previous local/global } \\
\text { best positions of all } \\
\text { particles }\end{array}$ & $\begin{array}{l}\text { The pheromone levels } \\
\text { associated with the } \\
\text { path trails }\end{array}$ & $\begin{array}{l}\text { The dance which is } \\
\text { performed by employed } \\
\text { bee's. }\end{array}$ & $\begin{array}{l}\text { Variation of light } \\
\text { intensity and } \\
\text { formulation of the } \\
\text { attractiveness }\end{array}$ \\
\hline Application area & $\begin{array}{l}\text { Function optimization, } \\
\text { artificial neural network } \\
\text { training, fuzzy system } \\
\text { control, Grammatical } \\
\text { Herding, mobile sensor } \\
\text { navigation }\end{array}$ & $\begin{array}{l}\text { Traveling Salesman } \\
\text { Problem, Scheduling, } \\
\text { Network Model } \\
\text { Problem, Vehicle } \\
\text { routing, Set problem }\end{array}$ & $\begin{array}{l}\text { Clustering, neural network } \\
\text { training, structural } \\
\text { optimization, multi-level } \\
\text { thresholding, face pose } \\
\text { estimation }\end{array}$ & $\begin{array}{l}\text { Digital Image } \\
\text { Compression and } \\
\text { Image Processing, } \\
\text { Clustering, } \\
\text { Scheduling and } \\
\text { TSP, Antenna } \\
\text { Design }\end{array}$ \\
\hline
\end{tabular}

\section{ADVANTAGES \& DISADVANTAGES}

\subsection{An Analysis on the Advantages and Disadvantages of the Swarm Intelligence}

Advantages of the Swarm Intelligence:

- Agents are simple, with minimal behaviour and memory.

- Control is decentralized; there is no global information in the system.

- Failure of individual agents is tolerated; emergent behaviour is robust with respect to individual failure

- Agents are not goal directed; they react rather than plan extensively.

- Agents can react to dynamically changing environments.

\section{Disadvantages of the Swarm Intelligence:}

- Collective behaviour cannot be inferred from individual agent behaviour. This implies that observing single agents will not necessarily allow swarm-defeating behaviour to be chosen. (This can be viewed as an advantage too from an aggressive point of view).
- Individual behaviour looks like noise as action choice is stochastic.

- Designing swarm-based systems is hard. There are almost no analytical mechanisms for design.

- Parameters can have a dramatic effect on the emergence (or not) of collective behaviour [30]. 


\subsection{An Analysis on the Advantages and Disadvantages of the Swarm Intelligence Algorithms}

\begin{tabular}{|c|c|c|}
\hline $\begin{array}{l}\text { ALGOR- } \\
\text { ITHMS }\end{array}$ & ADVANTAGES & DISADVANTAGES \\
\hline PSO & $\begin{array}{l}\text { PSO is based on the intelligence. It can be applied into } \\
\text { both scientific research and engineering use. } \\
\text { - PSO is easy to implement and there are few parameters } \\
\text { to adjust, it occupies the bigger optimization ability and } \\
\text { it can be completed easily.. } \\
\text { PSO have no overlapping and mutation calculation. The } \\
\text { search can be carried out by the speed of the particle. } \\
\text { During the development of several generations, only the } \\
\text { most optimist particle can transmit information onto the } \\
\text { other particles, and the speed of the researching is very } \\
\text { fast. }\end{array}$ & $\begin{array}{l}\text { Achieve optimality convergence strongly influenced by } \\
\text { the inertia weight. } \\
\text { When the algorithm converges, the fixed values of the } \\
\text { parameters might cause the unnecessary fluctuation of } \\
\text { particles } \\
\text { The method cannot work out the problems of scattering } \\
\text { and optimization. } \\
\text { Premature convergence and slow convergence in terms } \\
\text { of the multi-modal function optimization problem } \\
\text { solving process }\end{array}$ \\
\hline $\mathrm{ACO}$ & $\begin{array}{l}\text { - Ants are good masters in search and exploitation. } \\
\text { - ACO can be used in dynamic applications. } \\
\text { - Positive Feedback leads to rapid discovery of good } \\
\text { solutions. } \\
\text { - Efficient for Travelling Salesman Problem and similar } \\
\text { problems } \\
\text { - Distributed computation avoids premature convergence }\end{array}$ & $\begin{array}{l}\text { Theoretical analysis is difficult } \\
\text { Probability distribution changes by iteration } \\
\text { Sequences of random decisions (not independent) } \\
\text { Research is experimental rather than theoretical } \\
\text { Time to convergence uncertain (but convergence is } \\
\text { guaranteed!) }\end{array}$ \\
\hline $\mathrm{ABC}$ & $\begin{array}{l}\text { - Employing fewer control parameters. } \\
\text { - Strong robustness, fast convergence and high flexibility. } \\
\text { - It can be used for solving multidimensional and } \\
\text { multimodal optimization problem } \\
\text { - Global optimization and easy recognition. } \\
\text { - The structure of the algorithm is favourable for parallel } \\
\text { processing, thus saving time. } \\
\text { It conducts both global search and local search in each } \\
\text { iteration, and as a result the probability of finding the } \\
\text { optimal is significantly increase }\end{array}$ & $\begin{array}{l}\text { - Lack of use of secondary information about the problem } \\
\text { (gradients). } \\
\text { - High number of objective function evaluations. } \\
\text { - The population of solutions increases the computational } \\
\text { cost due to slowdown, many iterations and memory } \\
\text { capacity required. } \\
\text { The possibility of losing relevant information on the } \\
\text { behaviour of the function to be optimized. } \\
\text { Computational complexity is high at later stage } \\
\text { Poor convergence rate and local optimizing. }\end{array}$ \\
\hline FA & $\begin{array}{l}\text { High convergence rate. } \\
\text { Ever agent i.e. firefly works almost independently and } \\
\text { finds a better position for itself in consideration with its } \\
\text { current position as well as the position of other fireflies. } \\
\text { Thus, it escapes from the local optima and finds a } \\
\text { global optimum is less number of iterations. } \\
\text { Robust algorithm. } \\
\text { It is thus particularly suitable for parallel } \\
\text { implementation. }\end{array}$ & $\begin{array}{l}\text { - Trapping into several local optimums } \\
\text { Firefly algorithm parameters are set fixed and they do } \\
\text { not change with the time } \\
\text { - Firefly algorithm does not memorize or remember any } \\
\text { history of better situation for each firefly and this causes } \\
\text { them to move regardless of its previous better situation, } \\
\text { and they may end up missing their situations. } \\
\text { - Slow convergence speed. }\end{array}$ \\
\hline
\end{tabular}

\section{CONCLUSION}

As the mobile robots have become popular, the importance of path planning is much increased. Many techniques have been proposed to address this problem. In this paper we reviewed several swarm intelligence algorithm to know the recent development in the field of path planning of mobile robots. We explained every technique in brief and their respective algorithms in common steps. Each of the existing approaches for the path planning has its own advantages and disadvantages. This is because each algorithm is for a specific goal and considers the priority among different performance criteria such as time for path traversal, number of turns in the resultant path, complexity of the environment and proximity of obstacles.

\section{REFERENCES}

[1] Sierakowski, Cezar A., and Leandro dos S. Coelho. "Study of two swarm intelligence techniques for path planning of mobile robots." IFAC World Congress 2005.

[2] Binitha, S., and S. Siva Sathya. "A Survey of Bio inspired Optimization Algorithms." International Journal of Soft Computing and Engineering (IJSCE), ISSN (2012): 2231-2307.

[3] Bhattacharjee, P.; Rakshit, P.; Goswami, I.; Konar, A.; Nagar, A.K., "Multi-robot path-planning using artificial bee colony optimization algorithm," Nature and Biologically Inspired Computing (NaBIC), 2011 Third World Congress on , vol., no., pp.219,224, 19-21 Oct. 2011. 
[4] Saffari, M. H.; Mahjoob, M.J., "Bee colony algorithm for real-time optimal path planning of mobile robots," Soft Computing, Computing with Words and Perceptions in System Analysis, Decision and Control, 2009. ICSCCW 2009. Fifth International Conference on , vol., no., pp.1,4, 2-4 Sept. 2009

[5] Gengqian Liu; Tiejun Li; Yuqing Peng; Xiangdan Hou, "The Ant Algorithm for Solving Robot Path Planning Problem," Information Technology and Applications, 2005. ICITA 2005. Third International Conference on, vol.2, no., pp.25,27, 4-7 July 2005.

[6] Khatib, O., Real-Time Obstacle Avoidance for Manipulators and Mobile Robots, 5, 1986. The International Journal of Robotics Research: p. 90- 98.

[7] Xin, D., Hua-Hua C, Wei K.G., , Neural Network and Genetic Algorithm Based Global Path Planning in A Static Environment. Journal of Zhejiang University Science, 2005. 6A: p. 549-554.

[8] Zelinsky, A., Yuta S. A unified approach to planning, sensing and navigation for mobile robots. in 3rd Int. Symposium on Experimental Robotics. 1993. Kyoto, Japan.

[9] 14. Warren, C.W., Fast path planning using modified A* Method. IEEE Transactions on Systems, Man and Cybernetics, , 1993.

[10] Stentz, A. Optimal and Efficient Path Planning for Partially-Known Environments. in IEEE International Conference on Robotics and Automation. 1994.

[11] Netnevitsky, M., Artificial Intelligence: A guide to intelligent Systems. 2nd Ed ed. 2002: Addison-Wesley.

[12] Goss, S., Aron, S., Deneubourg, J.L., and Pasteels, J.M. (1989). Self-organized Shortcuts in the Argentine Ant. Naturwissenchaften Issue 76, pg. 579-581. SpringerVerlag

[13] Hwan-il Kang; Byunghee Lee; Kabil Kim, "Path Planning Algorithm Using the Particle Swarm Optimization and the Improved Dijkstra Algorithm," Computational Intelligence and Industrial Application, 2008. PACIIA '08. Pacific-Asia Workshop on, vol.2, no., pp.1002,1004, 19-20 Dec. 2008

[14] Yarmohamadi, Maryam, H. Haj Seyyed Javadi, and Hossein Erfani. "Improvement of Robot Path Planning Using Particle Swarm Optimization in Dynamic Environments with Mobile Obstacles and Target." Advanced Studies in Biology 3.1 (2011): 43-53.

[15] Nasrollahy, A.Z.; Javadi, H., "Using Particle Swarm Optimization for Robot Path Planning in Dynamic Environments with Moving Obstacles and Target," Computer Modeling and Simulation, 2009. EMS '09. Third UKSim European Symposium on , vol., no., pp.60,65, 25-27 Nov. 2009.

[16] Song-Hiang Chia; Kuo-Lan Su; Jr-Hung Guo; ChengYun Chung, "Ant Colony System Based Mobile Robot Path Planning," Genetic and Evolutionary Computing (ICGEC), 2010 Fourth International Conference on , vol., no., pp.210,213, 13-15 Dec. 2010

[17] Selvi, V., and R. Umarani. "Comparative analysis of ant colony and particle swarm optimization techniques."
International Journal of Computer Applications 5.4 (2010): 1-6

[18] Wen, Zhi-qiang, and Zi-xing Cai. "Global path planning approach based on ant colony optimization algorithm." JOURNAL-CENTRAL SOUTH UNIVERSITY OF TECHNOLOGY-ENGLISH EDITION- 13.6 (2006): 707.

[19] Oliveira, IMS de, Roberto Schirru, and J. A. C. C. Medeiros. "On the Performance of an Artificial Bee Colony Optimization Algorithm applied to the accident diagnosis in a PWR Nuclear Power Plant." International Nuclear Atlantic Conference. 2009.

[20] Saffari, M. H.; Mahjoob, M.J., "Bee colony algorithm for real-time optimal path planning of mobile robots," Soft Computing, Computing with Words and Perceptions in System Analysis, Decision and Control, 2009. ICSCCW 2009. Fifth International Conference on , vol., no., pp.1,4, 2-4 Sept. 2009

[21] Lin, Jiann-Horng, and Li-Ren Huang. "Chaotic bee swarm optimization algorithm for path planning of mobile robots." Proceedings of the 10th WSEAS international conference on evolutionary computing. World Scientific and Engineering Academy and Society (WSEAS), 2009.

[22] Butani, Ravi C., Bhavin D. Gajjar, and Rajesh A. Thakker. "Performance evaluation of Particle Swarm Optimization (PSO) and Artificial Bee Colony (ABC) Algorithm". International Conference on Advanced Computing, Communication and Networks'11.

[23] Yousif, A., et al. "Scheduling Jobs on Grid Computing using Firefly Algorithm." Journal of Theoretical and Applied Information Technology 33.2 (2011): 155-164.

[24] Nandy, Sudarshan, Partha Pratim Sarkar, and Achintya Das. "Analysis of a Nature Inspired Firefly Algorithm based Back-propagation Neural Network Training." arXiv preprint arXiv:1206.5360 (2012).

[25] Farahani, Sh M., et al. "A Gaussian Firefly Algorithm." International Journal of Machine Learning and Computing 1.5 (2011): 448-453.

[26] Liu, Chang, Zhongqiang Gao, and Weihua Zhao. "A New Path Planning Method Based on Firefly Algorithm." Computational Sciences and Optimization (CSO), 2012 Fifth International Joint Conference on. IEEE, 2012.

[27] Farahani, S., et al. "An Improved Firefly Algorithm with Directed Movement." Proceedings of 4th IEEE International Conference on Computer Science and Information Technology, Chengdu. 2011.

[28] Nandy, Sudarshan, et al. "Agent based adaptive firefly back-propagation neural network training method for dynamic systems." Hybrid Intelligent Systems (HIS), 2012 12th International Conference on. IEEE, 2012.

[29] Wang, Gaige, et al. "A modified firefly algorithm for UCAV path planning." International Journal of Hybrid Information Technology 5.3 (2012): 123-144.

[30] Utkarsh Jaiswal, Shweta Aggarwal. "Ant Colony Optimization". International Journal of Scientific \& Engineering Research Volume 2, Issue 7, July-2011 1 ISSN 2229-5518 